EXTENDED REPORT

\title{
Association between baseline radiographic damage and improvement in physical function after treatment of patients with rheumatoid arthritis
}

\author{
F C Breedveld, C Han, M Bala, D van der Heijde, D Baker, A F Kavanaugh, R N Maini, \\ P E Lipsky
}

See end of article for authors' affiliations

Correspondence to: Dr F Breedveld,

Department of

Rheumatology, Leiden

University Medical Centre,

Leiden, Netherlands;

f.c.breedveld@lumc.nl

Accepted 19 April 2004

Published Online First

29 July 2004

Objectives: To identify factors associated with poor physical function in rheumatoid arthritis and to assess whether baseline joint damage has an impact on improvement in physical function during infliximab treatment.

Methods: 428 patients with active rheumatoid arthritis despite methotrexate treatment received methotrexate alone or with infliximab ( $3 \mathrm{mg} / \mathrm{kg}$ or $10 \mathrm{mg} / \mathrm{kg}$ every four or eight weeks) for 54 weeks (the ATTRACT trial). Data on clinical outcomes and physical function (assessed by the health assessment questionnaire (HAQ)) were collected. Structural damage was assessed using the van der Heijde modification of the Sharp score. Odds ratios (OR) for factors associated with severe functional disability $(\mathrm{HAQ} \geqslant 2.0)$ at baseline were estimated using multiple logistic regression analyses, and baseline factors related to the change in physical function after treatment at week 54 were determined.

Results: Baseline radiographic scores were correlated with baseline $\mathrm{HAQ}$ scores. After adjustment for demographic characteristics in the logistic regression model, baseline disease activity scores, radiological joint damage, fatigue, and morning stiffness were found to be associated with severe functional disability ( $\mathrm{HAQ}>2.0$ ), with $\mathrm{OR}$ values of 2.00 (1.53 to 2.63), 1.82 (1.15 to 2.87), 1.19 (1.05 to 1.34), and 1.07 (1.01 to 1.13), respectively. In multiple linear regression analysis, physical disability, joint damage, and fatigue at baseline were correlated with less improvement in physical function after treatment. Infliximab treatment was associated with greater improvement in physical function.

Conclusions: Greater joint damage at baseline was associated with poorer physical function at baseline and less improvement in physical function after treatment, underlining the importance of early intervention to slow the progression of joint destruction.

$\mathrm{P}$

hysical function in patients with rheumatoid arthritis deteriorates progressively throughout the course of the disease, starting with functional limitations and progressing to physical disability if no effective treatment intervention is introduced in a timely manner. ${ }^{1}$ Approximately $50 \%$ of patients with rheumatoid arthritis are expected to experience enough loss of function to cause work disability within 10 years after disease onset. ${ }^{2}$ Previous studies have shown that multiple factors are associated with functional disability in patients with rheumatoid arthritis, including disease activity, radiographic damage, co-morbidities, and socioeconomic and psychological factors. ${ }^{3-6}$

The association of radiographic joint damage with physical function may vary with disease phase. In the early stages of rheumatoid arthritis, the link between joint damage and physical function is not well established. ${ }^{7-11}$ However, in established disease, joint damage is known to be a major determinant of functional disability. ${ }^{4-6}$ It is not clear whether pre-existing joint damage affects the extent of improvement in physical function that could be achieved with highly effective treatment. Understanding the factors associated with improvement in physical function may have implications for appropriate disease management of this disease.

In this post-hoc analysis, data collected from ATTRACT (the anti-TNF trial in rheumatoid arthritis with concomitant therapy) were used to evaluate the association between radiological joint damage and physical function at baseline, as well as the association of baseline radiological damage with improvement in physical function after one year of treatment.

\section{METHODS}

\section{Patient eligibility}

Patient enrolment criteria and the design of the study have been described in detail previously. ${ }^{12}{ }^{13}$ Briefly, patients with rheumatoid arthritis who had active disease despite the use of concomitant methotrexate were randomly assigned to receive methotrexate alone or methotrexate plus one of four infliximab treatment regimens $(3 \mathrm{mg} / \mathrm{kg}$ or $10 \mathrm{mg} / \mathrm{kg}$ every four or eight weeks, after a three dose induction phase with infusions at weeks 0,2 , and 6). Treatment outcomes were collected at four week intervals from baseline to week 54 .

\section{Clinical and radiographic evaluation}

Outcomes, including the number of swollen and tender joints and the erythrocyte sedimentation rate (ESR), were collected from baseline to week 54. Patient and evaluator global assessments of disease activity and patient assessments of fatigue were made using a visual analogue scale (ranging from 0 to 10). The disease activity score based on 28 joints (DAS 28), calculated as $0.56^{*} \sqrt{ }$ (tender joint count)

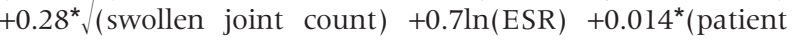
global assessment of disease activity), ${ }^{14}$ was used as a measure of rheumatoid arthritis disease activity. Physical function was measured using the health assessment questionnaire (HAQ). ${ }^{15}$ Structural damage of the hands and feet was assessed using the van der Heijde modification of the Sharp score (vdH-Sharp score, ranging from 0 to 440 ). ${ }^{16}$ The

Abbreviations: ATTRACT, anti-TNF trial in rheumatoid arthritis with concomitant therapy; $\mathrm{HAQ}$, health assessment questionnaire 
Table 1 Association of baseline radiographic score with health assessment questionnaire score and tender joint and swollen joint counts at baseline

\begin{tabular}{lllll}
\hline $\begin{array}{l}\text { Baseline total radiological } \\
\text { score }\end{array}$ & HAQ & $\begin{array}{l}\text { Disease } \\
\text { activity score }\end{array}$ & Tender joint count & Swollen joint count \\
\hline $\begin{array}{l}\text { s20.5 } \\
20.6 \text { to } 51.5\end{array}$ & $1.57(0.54)$ & $6.5(0.96)$ & $30.7(16.2)$ & $19.2(11.3)$ \\
51.6 to 113 & $1.62(0.66)$ & $6.7(0.99)$ & $30.3(16.5)$ & $21.6(11.5)$ \\
$>113$ & $1.76(0.62)$ & $6.9(1.05)$ & $35.2(16.9)$ & $23.7(12.7)$ \\
Correlation coefficient* & $1.86(0.64)$ & $6.7(1.06)$ & $32.3(17.0)$ & $26.2(11.9)$ \\
\hline & $0.18(p<0.001)$ & $0.12(p=0.13)$ & $0.08(p>0.05)$ & $0.26(p<0.001)$ \\
\hline $\begin{array}{l}\text { Values are mean (SD). } \\
\text { *Spearman's correlation coefficients of baseline total radiographic score with } \mathrm{HAQ} \text {, disease activity score, and }\end{array}$ \\
swollen and tender joint counts. \\
HAQ, health assessment questionnaire.
\end{tabular}

total vdH-Sharp score was the average of the scores from two blinded readers and is referred to in this paper as the total radiographic score.

\section{Statistical analysis}

Patients with radiographs of both the hands and feet at baseline and week 54 were included in the analysis. Data from patients in both the placebo and infliximab groups were used in the analysis, with the assumption that the impact of baseline factors on improvement in physical function was similar for the two treatment groups. This assumption was tested by including treatment group as a covariate in the regression model. In the statistical model exploring the factors associated with baseline $\mathrm{HAQ}$, multivariate linear regression and logistic regression analyses were employed to adjust for the confounding effect of correlated variables.

In the logistic regression analysis, patients were classified into two groups based on the HAQ scores at baseline: HAQ $<2.0$ (moderate disability) and HAQ $\geqslant 2.0$ (severe disability). This value was chosen based on data indicating that an HAQ score of 2 or higher was correlated with severe disability. ${ }^{17}$ The odds ratios (OR) and confidence intervals for severe disability were estimated. After treatment at week 54, the correlation of change in physical function with baseline clinical and radiographic joint damage was analysed using multiple linear regression models. DAS 28 was used to represent disease activity in all multiple regression models. Erythrocyte sedimentation rate (ESR), numbers of swollen and tender joints, and patient assessments of disease activity were not included in the model because these variables are incorporated in the DAS 28 calculation.

Missing values in clinical measures other than radiographic scores at week 54 were imputed using the "last observation carried forward" method. Analysis of variance on the van der Waerden normal scores was used to compare the results among patient groups for continuous variables. ${ }^{18}$ For categorical response variables, patient group comparisons were made using the $\chi^{2}$ test. Statistical analyses employed the SAS system (SAS Institute, Cary, North Carolina, USA). All statistical tests were two sided, with $\alpha=0.05$.
Table 3 Baseline variables significantly associated with baseline health assessment questionnaire (HAQ) scores in the linear regression model

\begin{tabular}{lrll}
\hline Explanatory variable & $\boldsymbol{\beta}$ & SE $(\boldsymbol{\beta})$ & $\boldsymbol{p}$ Value \\
\hline Male sex & -0.202 & 0.064 & 0.0016 \\
Radiographic score (0-440) & 0.001 & 0.000 & 0.0002 \\
Disease activity score (0-10) & 0.202 & 0.029 & $<0.0001$ \\
Morning stiffness (min) & 0.012 & 0.006 & 0.0404 \\
Fatigue (0-10) & 0.064 & 0.013 & $<0.0001$ \\
\hline
\end{tabular}

$\beta$, estimated coefficient; SE ( $\beta$ ), estimated standard error of the $\beta$.

\section{RESULTS}

Association of baseline radiological joint damage with baseline $H A Q$ score and baseline disease activity Patients were categorised into four groups of approximately the same size based on quartiles of baseline radiographic scores. Compared with patients in the lowest quartile of radiographic score $(\leqslant 20.5)$, patients in the highest quartile of radiographic score $(>113)$ had a significantly higher HAQ score $(1.86 \vee 1.57, \mathrm{p}<0.05)$, more swollen $(26.2 \vee 19.2$, $\mathrm{p}<0.05)$ and tender joints $(32.2 v 30.7, \mathrm{p}>0.05)$, and more severe disease activity $(6.7 v 6.5, \mathrm{p}<0.05)$. Furthermore, baseline radiographic damage was significantly correlated with baseline HAQ scores $(r=0.18, \mathrm{p}<0.001)$ and swollen joint counts $(r=0.26, \mathrm{p}<0.001)$ (table 1). The correlation between HAQ scores and radiographic scores increased with longer disease duration ( $<10$ years, $r=0.14 v \geqslant 10$ years, $r=0.20)$; whereas, the correlation between HAQ scores and disease activity scores decreased with longer disease duration $(<10$ years, $r=0.50 v \geqslant 10$ years, $r=0.40$ ) (table 2 ).

In the linear regression model, sex, baseline joint damage, disease activity score, morning stiffness, and fatigue score were significantly correlated with baseline HAQ score (table 3).

In the logistic regression model, a dichotomous variable representing severe functional disability (HAQ $\geqslant 2.0)$ was used as the dependent variable, and age, male sex (yes or no),

Table 2 Spearman correlations between baseline $H A Q$ scores and baseline radiographic scores or disease activity by disease duration

\begin{tabular}{llll}
\hline \multirow{2}{*}{ Comparison } & \multicolumn{2}{l}{ Disease duration (years) } \\
\cline { 2 - 4 } & $<10$ & $\geqslant 10$ & Total \\
\hline HAQ scores $v$ radiographic score & $0.14(p<0.05)$ & $0.20(p=0.01))$ & $0.18(p<0.01)$ \\
HAQ scores $v$ disease activity score & $0.50(p<0.01)$ & $0.40(p<0.01)$ & $0.46(p<0.01)$ \\
\hline$H A Q$, health assessment questionnaire. & & \\
\hline
\end{tabular}


Table 4 Baseline variables significantly associated with severe physical disability (health assessment questionnaire score $\geqslant 2.0$ ) in the logistic regression model

\begin{tabular}{|c|c|c|c|c|c|}
\hline Explanatory variable & $\beta$ & SE $(\beta)$ & p Value & OR & OR $95 \% \mathrm{Cl}$ \\
\hline Age (per year) & 0.025 & 0.010 & 0.02 & 1.004 & 1.01 to 1.05 \\
\hline Male sex & -0.780 & 0.292 & $<0.01$ & 0.46 & 0.26 to 0.81 \\
\hline Radiological joint damage (radiographic score $>50$ ) & 0.598 & 0.233 & 0.01 & 1.82 & 1.15 to 2.87 \\
\hline Disease activity score (per unit) & 0.694 & 0.139 & $<0.01$ & 2.00 & 1.53 to 2.63 \\
\hline Morning stiffness (per minute) & 0.065 & 0.029 & 0.02 & 1.07 & 1.01 to 1.13 \\
\hline Fatigue (per unit) & 0.170 & 0.062 & $<0.01$ & 1.19 & 1.05 to 1.34 \\
\hline
\end{tabular}

disease duration, disease activity (DAS 28 score), radiographic score $>50$ (yes or no), morning stiffness (minutes), and fatigue score were used as independent variables. In the final model using stepwise selection, baseline disease activity and radiographic joint damage were the most significant risk factors for severe functional disability at baseline. The odds ratio for severe functional disability for patients with severe joint damage (radiographic score $>50)$ was $1.82 \quad(95 \%$ confidence interval $(\mathrm{CI}), 1.15$ to 2.87$)(\mathrm{p}=0.01)$. The odds ratio for severe functional disability for patients with higher disease activity (per unit increase) was 2.0 ( 1.53 to 2.63) $(\mathrm{p}<0.01)$. Fatigue and morning stiffness were also significantly associated with severe functional disability. Men were less likely to have severe functional disability than women. Disease duration was not a significant factor in the model after adjusting for the other factors; therefore it was not incorporated into the model (table 4).

\section{Association of baseline joint damage and treatment outcomes}

The mean per cent improvement in physical function was significantly associated with baseline radiographic scores, with patients in the highest radiographic score quartile having significantly smaller improvements in HAQ than those in the lowest radiographic score quartile (16\% v 32\%, $\mathrm{p}<0.01$ ). In contrast, the mean per cent improvement in disease activity, the number of tender joints, and the number of swollen joints was not significantly different among groups defined by radiographic score quartiles (fig 1).

As patients in the infliximab plus methotrexate group had greater improvement in physical function in each radiographic score quartile than those in the placebo plus methotrexate group, the correlation of improvement in physical function at week 54 with baseline factors was further analysed using a multiple linear regression analysis,

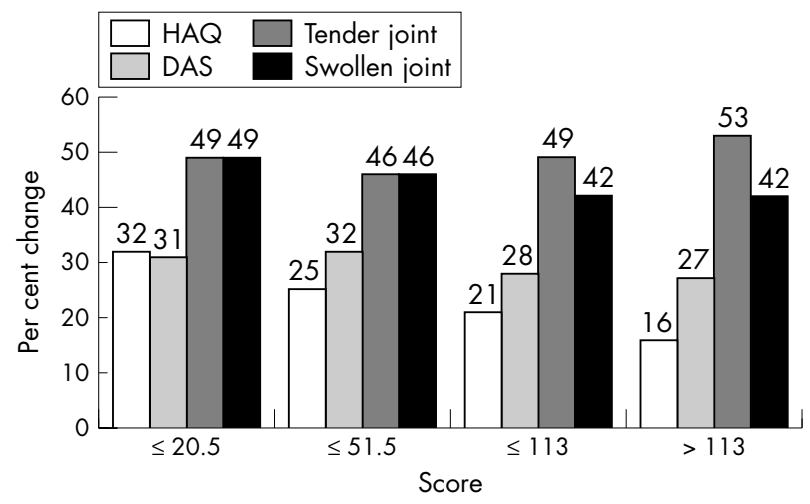

Figure 1 Per cent improvement in health assessment questionnaire (HAQ) score, disease activity score (DAS), and tender and swollen joint counts from baseline to week 54 by baseline radiological score. with treatment as one of the covariates. In the final regression model using stepwise model selection, infliximab treatment was significantly correlated with improvement in HAQ score at week 54. Age, baseline HAQ scores, baseline joint damage, and baseline fatigue were also independently associated with the change (improvement) in physical function, regardless of the treatment group assignment (table 5). Greater radiographic joint damage and more severe fatigue at baseline were associated with less improvement in physical function at week $54(\mathrm{p}<0.05)$. In addition, patients with greater disability at baseline showed a greater improvement in physical function after treatment at week 54 $(p<0.01)$. Baseline disease activity and morning stiffness were not significant factors in predicting improvement in physical function at week 54 after adjustment for other baseline factors; therefore they were not incorporated into the model.

\section{DISCUSSION}

Rheumatoid arthritis is a chronic, progressive, and destructive disorder. Functional disability increases rapidly in affected individuals, such that about half will experience work disability within 10 years of diagnosis. ${ }^{2}$ Previous studies have shown that multiple clinical and non-clinical variables are associated with functional disability, the most important being disease activity and radiographic joint damage. ${ }^{36}$ In the early stage of the disease, functional ability may be influenced more by disease activity than by radiographic joint damage. ${ }^{7}$ However, as the disease progresses, joint damage becomes a more dominant factor in determining physical function. ${ }^{6}$ Clarke et $a l^{3}$ reported that the correlation between radiographic scores and HAQ scores tends to increase with disease duration, from 0.15 after 0 to 5 years of disease onset to 0.42 after 10 to 15 years. The ATTRACT baseline data showed a similar trend, with the correlation between HAQ scores and radiographic scores increasing from 0.14 to 0.20 with an increase in disease duration $(<10$ years $v$ $\geqslant 10$ years).

In general, traditional disease modifying antirheumatic drug (DMARD) treatments can slow disease progression but

Table 5 Baseline factors significantly associated with improvement in health assessment questionnaire score from baseline to week 54 in the multiple linear regression analysis

\begin{tabular}{lrrr}
\hline Baseline characteristic & $\boldsymbol{\beta}$ & SE $(\boldsymbol{\beta})$ & p Value \\
\hline Age (years) & -0.009 & 0.003 & 0.002 \\
Baseline HAQ score & 0.180 & 0.050 & $<0.001$ \\
Baseline radiographic score & -0.001 & 0.000 & 0.019 \\
Baseline fatigue score & -0.035 & 0.014 & 0.014 \\
Treatment (infliximab) & 0.302 & 0.070 & $<0.001$ \\
\hline
\end{tabular}

$\beta$, estimated coefficient; SE ( $\beta)$, estimated standard error of the $\beta$. $H A Q$, health assessment questionnaire. 
may not prevent the bone and cartilage erosion associated with rheumatoid arthritis. ${ }^{19}$ Unchecked progression of the disease can eventually lead to functional impairment. Thus controlling only the clinical signs and symptoms may not be adequate to retain the patient's long term physical function. Understanding and managing the risk factors related to long term functional impairment is critical for better treatment outcomes.

In the past decade, joint damage as assessed by radiography has been considered one of the critical measurements in the evaluation of disease severity and treatment efficacy in clinical trials. ${ }^{20}$ An association has been observed not only between joint damage and severe functional loss, but also between joint damage and loss of employability ${ }^{21}$ and higher mortality in the rheumatoid population. ${ }^{22}$ ATTRACT data showed that radiographic joint damage was associated with unemployment, and that patients with a radiographic score of more than 50 had a much lower probability of being employed full time than those with lower radiographic scores. ${ }^{23}$ As demonstrated in this analysis, baseline radiographic joint damage is related to baseline physical function and is also a significant predictor of improvement in physical function after treatment. Patients with radiographic scores of 20.5 or less had better improvement in physical function (32\%) from baseline to week 54 than those with radiographic scores of more than 113 (16\%), even though both patient groups had similar improvement in disease activity scores (31\% v 27\%). The ATTRACT trial was ideally suited to this study, as the range of radiographic scores at baseline in ATTRACT was larger than that of the study populations in other trials. The results of this analysis strongly support the association between radiographic damage and physical disability in patients with established disease. Furthermore, the results indicate that physical disability caused by joint damage from erosions and joint space narrowing is less likely to be reversible at later disease stages.

A major limitation of the study was that it was a post hoc exploratory analysis, examining the association between joint damage and physical function. Any conclusions regarding causal relations based on these results should be made with caution. Another limitation was that only patients with moderate to severe rheumatoid arthritis who were inadequately responding to methotrexate were enrolled in the ATTRACT study. Thus caution should be exercised in extrapolating these results beyond this patient population.

\section{Conclusions}

The results of our analysis show that the improvement in physical function after one year of treatment in patients with moderate to severe rheumatoid arthritis was correlated with the degree of radiographic joint damage already evident at baseline. If this indicates the relatively lower reversibility of functional loss resulting from structural damage, then these results underline the importance of early treatment to limit joint damage.

\section{ACKNOWLEDGEMENTS}

The ATTRACT study was sponsored by Centocor Inc. FCB, AFK, RNM, and DvdH have received research support from and served as consultants to Centocor Inc. $\mathrm{CH}, \mathrm{MB}$, and $\mathrm{DB}$ are employees of Centocor Inc.

\section{Authors' affiliations}

F C Breedveld, Department of Rheumatology, Leiden University Medical Centre, Leiden, Netherlands
C Han, M Bala, Outcomes Research, Centocor Inc, Malvern, Pennsylvania, USA

D van der Heijde, Department of Internal Medicine/Rheumatology, University Hospital Maastricht, Maastricht, Netherlands D Baker, Clinical Research and Development, Centocor Inc A F Kavanaugh, Division of Rheumatology, Allergy, and Immunology, University of California San Diego, La Jolla, California, USA R N Maini, Kennedy Institute of Rheumatology, Imperial College of Science, Technology, and Medicine, London, UK

P E Lipsky, National Institute of Arthritis and Musculoskeletal and Skin Diseases, National Institutes of Health, Bethesda, Maryland, USA

\section{REFERENCES}

1 Kavanaugh AF, Lipsky PE. Rheumatoid arthritis. In: Rich RR, Fleisher TA, Schwartz B, Shearer W, et al. Clinical immunology: principles and practice. St Louis: Mosby Year Books, 1996:1093-116.

2 Wolfe F, Hawley DJ. The long-term outcomes of rheumatoid arthritis: work disability; a prospective 18 year study of 823 patients. J Rheumatol 1998;25:2108-17.

3 Clarke AE, St-Pierre Y, Joseph L, Penrod JT, Sibley MH, Genant HK. Radiographic damage in rheumatoid arthritis correlates with functional disability but not direct medical costs. J Rheumatol 2001;28:2416-24.

4 Escalante A, del Rincon I. How much disability in rheumatoid arthritis is explained by rheumatoid arthritis? Arthritis Rheum 1999;42:1712-21.

5 Molenaar ET, Voskuyl AE, Dijkmans BA. Functional disability in relation to radiological damage and disease activity in patients with rheumatoid arthritis in remission. J Rheumatol 2002;29:267-70.

6 Drossaers-Bakker KW, de Buck M, van Zeben D, Zwinderman $A H$, Breedveld FC, Hazes JMW. Long-term course and outcome of functional capacity in rheumatoid arthritis: the effect of disease activity and radiologic damage over time. Arthritis Rheum 1999;42:1854-60.

7 Guillemin F, Briancon S, Pourel J. Functional disability in rheumatoid arthritis: two different models in early and established disease. J Rheumatol 1992;19:366-9.

8 Guillemin F, Suurmeijer T, Krol B, Bombardier C, Briançon S, Doeglas D, et al. Functional disability in early rheumatoid arthritis: description and risk factors. J Rheumatol 1994;21:1051-5

9 van Leeuwen MA, van der Heijde DMFM, van Rijswijk MH, Houtman PM, van Riel PLCM, van de Putte LBA, et al. Interrelationship of outcome measures and process variables in early rheumatoid arthritis. A comparison of radiologic damage, physical disability, joint counts, and acute phase reactants. J Rheumatol 1994;21:425-9.

10 van der Heijde A, Remme CA, Hofman DM, Jacobs JWG, Bijlsma JWJ. Prediction of progression of radiologic damage in newly diagnosed rheumatoid arthritis. Arthritis Rheum 1995;38:1466-74.

11 Kirwan JR. Conceptual issues in scoring radiographic progression in rheumatoid arthritis. J Rheumatol 1999;26:720-5.

12 Maini R, St Clair EW, Breedveld F, Kalden J, Weisman M, Smolen J, et al. Infliximab (chimeric anti-tumour necrosis factor- $\alpha$ monoclonal antibody) versus placebo in rheumatoid arthritis patients receiving concomitant methotrexate: a randomised phase III trial. Lancet 1999;354:1932-9.

13 Lipsky PE, van der Heijde DM, St Clair EW, Furst DE, Breedveld FC, Kalden JR, et al. Infliximab and methotrexate in the treatment of rheumatoid arthritis. N Engl J Med 2000;343: 1594-602.

14 Prevoo ML, van't Hof MA, Kuper HH, van Leeuwen MA, van de Putte LB, van Riel PL. Modified disease activity scores that include twenty-eight-joint counts: development and validation in a prospective longitudinal study of patients with rheumatoid arthritis. Arthritis Rheum 1995;38:44-8.

15 Ramey DR, Raynauld JP, Fries JF. The health assessment questionnaire 1992: status and review. Arthritis Care Res 1992;5:119-29.

16 van der Heijde DM, van Leeuwen MA, van Riel PL, Koster AM, van't Hof MA, van Rijswijk MH, et al. Biannual radiographic assessments of hands and feet in a three-year prospective followup of patients with early rheumatoid arthritis. Arthritis Rheum 1992;35:26-34.

17 Bruce B, Fries JF. The Stanford Health Assessment Questionnaire: dimensions and practical applications. Health Qual Life Outcomes 2003;1:20-6.

18 Snedecor GW. Statistical methods, $7^{\text {th }}$ ed. lowa City: lowa State University Press, 1980.

19 Kalden JR. Expanding role of biologic agents in rheumatoid arthritis $J$ Rheumatol 2002;29(suppl 66):27-37.

20 van der Heijde D. Radiographic progression in rheumatoid arthritis: does it reflect outcome? Does it reflect treatment? Ann Rheum Dis 2001;60(suppl 3):iii47-50.

21 Sokka T, Pincus T. Markers for work disability in rheumatoid arthritis. $J$ Rheumatol $2001 ; 28: 1718-22$.

22 Choi HK, Wolfe F. Radiologic progression and mortality [abstract]. Arthritis Rheum 2001;44(suppl 9):S221.

23 Kavanaugh AF, Han C, Bala M, et al. Improvement in functional status results in increased employability and reduced costs of RA: analysis of the minimum clinically important difference in health assessment questionnaire in the ATTRACT study [abstract]. Arthritis Rheum 2002;46(suppl 9):S575 